\title{
Clinical outcomes, toxicity, and cosmesis in breast cancer patients with close skin spacing treated with accelerated partial breast irradiation (APBI) using multi-lumen/catheter applicators
}

\author{
Mani Akhtari, MD 1.2, Mirna Abboud, MD², Sean Szeja, MD',2, Ramiro Pino, PhD², Gary D. Lewis, MD!2, Barbara L. Bass, MD³. \\ Darlene M. Miltenburg, MD4, E. Brian Butler, MD², Bin S. Teh, MD² \\ 'Department of Radiation Oncology, University of Texas Medical Branch, Galveston, TX, 2Department of Radiation Oncology, Houston \\ Methodist Hospital, Cancer Center and Research Institute, Houston, TX, ${ }^{3}$ Department of Surgery, Houston Methodist Hospital, Houston, TX, \\ ${ }^{4}$ Texas Women's Comprehensive Breast Center, USA
}

\begin{abstract}
Purpose: Accelerated partial breast irradiation (APBI) using a single-lumen device is associated with better cosmetic outcomes if the spacing between the applicator and skin is $>7 \mathrm{~mm}$. However, there are no reports addressing the late toxicity and clinical outcomes in patients treated with single-entry multi-lumen/catheter applicators who had close skin spacing ( $7 \mathrm{~mm}$ or less). We undertook this study to report clinical outcome, acute and late toxicity as well as cosmesis of early stage breast cancer patients with close skin spacing treated with APBI using multi-lumen or multi-catheter devices.

Material and methods: This is a retrospective study of all breast cancer patients who had undergone APBI using single-entry multi-lumen/catheter devices in a single institution between 2008 to 2012. The study was limited to those with $\leq 7 \mathrm{~mm}$ spacing between the device and skin.

Results: We identified 37 patients and 38 lesions with skin spacing of $\leq 7 \mathrm{~mm}$. Seven lesions (18\%) had spacing of $\leq 3 \mathrm{~mm}$. Median follow-up was 47.5 months. There was one case of ipsilateral breast recurrence and one ipsilateral axillary recurrence. Based on RTOG criteria, 22 treated lesions experienced grade 1 and 9 lesions experienced grade 2 toxicity. Twenty-one lesions experienced late grade 1 toxicity. One patient had to undergo mastectomy due to mastitis. Twenty-four treated breasts showed excellent and 11 had good cosmetic outcome. Overall cosmesis trended towards a significant correlation with skin spacing. However, all patients with $\leq 3 \mathrm{~mm}$ skin spacing experienced acute and late toxicities.

Conclusions: Accelerated partial breast irradiation can be safely performed in patients with skin spacing of $\leq 7 \mathrm{~mm}$ using single-entry multi-lumen/catheter applicators with excellent cosmetic outcomes and an acceptable toxicity profile. However, skin spacing of $\leq 3 \mathrm{~mm}$ is associated with acute and late toxicity and should be avoided if possible.
\end{abstract}

Key words: APBI, breast cancer, skin spacing.

\section{Purpose}

Breast conservation therapy (BCT), which involves lumpectomy followed by adjuvant radiation therapy, has now become the standard of care in women with early stage breast cancer. However, historically, the majority of patients with early stage breast cancer have been treated with whole breast irradiation (WBI). Whole breast irradiation can require a long treatment time ranging anywhere from three to six weeks depending on the fractionation, which can be prohibitive for many patients. Additionally,
WBI covers areas of the breast, which are not necessarily at the highest risk of relapse [1]. Accelerated partial breast irradiation (APBI) utilizing single-entry multi-lumen or multi-catheter devices such as Contura ${ }^{\circledR}$ (Hologic Inc, Bedford, MA, USA) or SAVI ${ }^{\circledR}$ (Cianna Medical, Aliso Viejo, CA, USA), can treat a smaller volume at the highest risk of recurrence around the lumpectomy cavity in regimens typically lasting only five days. Additionally, patients treated with APBI report higher cosmetic satisfaction compared to a similar WBI cohort [2]. Due to these
Address for correspondence: Bin S. Teh, MD, Department of Radiation Oncology, Houston Methodist Hospital, Cancer Center and Research Institute, 6565 Fannin, DB1-077, 77030 Houston, Texas 77030, USA, phone: +1 713-441-4800, fax: +1 713-441-4493, $\bowtie$ e-mail: bteh@houstonmethodist.org
Received: 09.08.2016

Accepted: 07.12.2016

Published: 30.12.2016 
advantages, APBI has been gaining in popularity over the past decade, now being utilized in as many as $11 \%$ of patients older than 50 who undergo BCT [3].

In the American Society of Breast Surgeons' (ASBS) Mammosite ${ }^{\circledR}$ (Hologic Inc, Bedford, MA, USA) registry trial, device-to-skin spacing $>7 \mathrm{~mm}$ was associated with better cosmetic outcome [4]. Thus, close skin spacing $(\leq 7 \mathrm{~mm})$ has been since then feared to cause worse toxicity and produce inferior cosmetic outcomes. Given the increasing use of APBI, multiple consensus guidelines and patient selection criteria have been developed to allow for the selection of the most appropriate patients $[5,6,7,8,9]$. However, none of these guidelines include any selection factors or dose tolerance limits in regards to device-toskin spacing or maximum skin dose when multi-lumen or catheter devices are utilized. Niehoff et al. had shown that patients are at risk of developing telangiectasia if their device to skin spacing was between 7 to $12 \mathrm{~mm}$ but they did not include any patients with spacing of $<7 \mathrm{~mm}$ on their phase II trial [10]. Patients with close skin-spacing were included in the initial SAVI ${ }^{\circledR}$ experience but their outcomes were not reported separately [11]. Lee et al. have previously published their results regarding acute toxicity and early cosmetic outcomes in patients treated with multilumen devices [12]. However, besides the aforementioned data, there are no other clinical and toxicity outcomes for patients treated with close skin spacing using APBI. The purpose of this study is to examine our APBI cohort and report their outcomes to add to this growing body of evidence regarding its safety efficacy and cosmesis in patients with close skin spacing.

\section{Material and methods}

Institutional Review Board approval was obtained prior to initiation of the study. Medical records of all the patients treated with APBI using either Contura ${ }^{\circledR}$ or SAVI ${ }^{\circledR}$ between 2007 to 2013 were reviewed. Patients with device-to-skin spacing of less than or equal to $7 \mathrm{~mm}$ and follow-up longer than six months were selected. Basic demographics, disease characteristics, and treatment parameters were collected. All patients had undergone lumpectomy along with sentinel lymph node biopsy for invasive carcinoma prior to their treatment. All the Contura $^{\circledR}$ or SAVI ${ }^{\circledR}$ devices were placed by the surgeon via a closed cavity approach. The appropriate device was selected by the surgeon based on the lumpectomy cavity size and vendor guidelines. The device was inserted either through the surgical scar or through a separate incision. Ultrasound guidance was used to detect the seroma and align the route of insertion along the longest axis diameter of the cavity. Planning computed tomography (CT) simulation was performed 48-72 hours following device placement in our department (Brilliance Big Bore, Philips Healthcare, Andover, MA, USA). All patients were simulated with the arm on the affected side raised above their head in the supine position. A small amount of contrast $(0.5 \mathrm{cc})$ was added to the saline mixture filling the balloon for Contura ${ }^{\circledR}$ patients to improve visualization of the balloon on CT. BrachyVision treatment planning system (Varian, Palo Alto, CA, USA) was used for all of our treatment planning. The planning target volume for evaluation (PTV_EVAL) consisted of $1 \mathrm{~cm}$ of tissue surrounding the device but limited to $5 \mathrm{~mm}$ from the skin for the Contura ${ }^{\circledR}$ patients and $3 \mathrm{~mm}$ for the SAVI ${ }^{\circledR}$ patients if possible. During treatment planning, all attempts were made to limit the maximum dose to the skin to less than $125 \%$ and no more than $145 \%$ of the prescribed dose for the Contura ${ }^{\circledR}$ patients, and less than $100 \%$ and no more than $110 \%$ in the $\mathrm{SAVI}^{\circledR}$ patients. Other planning parameters included maximum rib dose of $<145 \%$ in Contura ${ }^{\circledR}$ patients and $<100 \%$ in SAVI ${ }^{\circledR}$ patients, $\mathrm{V}_{90}$ (volume of PTV_EVAL receiving $90 \%$ of prescribed dose) $>100 \%, \mathrm{~V}_{95}>95 \%$, and $\mathrm{V}_{100}>90 \%$ in all patients. We also attempted to minimize the $\mathrm{V}_{150}$ of normal breast tissue to $<50 \mathrm{cc}$ and $\mathrm{V}_{200}<10 \mathrm{cc}$. All lesions were treated to $34 \mathrm{~Gy}$ in 10 twice-daily treatments, six hours apart, and over five days.

Acute and late toxicities were graded based on the Radiation Oncology Therapy Group (RTOG) criteria [13]. Toxicities up to 90 days post-treatment were considered acute and "the remainder" were graded as late toxicities. Even though the near majority of toxicities measured were as related to skin or subcutaneous tissue, toxicities in all RTOG criteria were considered and the highest grade was assigned to the patient for further analysis. The final cosmetic outcome was determined by either the treating radiation oncologist or the breast surgeon and was graded based on the Harvard breast cosmesis scale [14]. The $\chi^{2}$ test was used to assess any significant correlation between skin spacing and outcomes.

\section{Results}

\section{Baseline characteristics}

In total forty-three patients were identified with device to skin distance of $\leq 7 \mathrm{~mm}$. Five patients were excluded due to follow-up less than 6 months. The sixth patient was excluded since she was converted to whole breast irradiation after 3 fractions, due to personal preference. Overall, 37 patients and 38 lesions (one patient had bilateral treatment) were identified as meeting our selection criteria and were analyzed. The baseline characteristics of our patient population are summarized in Table 1 . The median age at the time of the diagnosis was 62.5 years. The majority of our lesions $(92 \%)$ were treated with Contura ${ }^{\circledR}$. Three patients received neoadjuvant hormonal therapy prior to surgery, and $68 \%$ received adjuvant hormonal therapy. Represented histologies were mixed between ductal carcinoma in situ $(34 \%)$, invasive $(55 \%)$, or mixed subtypes $(11 \%)$. All our patients were staged as either Tis or T1, and all lesions with invasive subtypes underwent sentinel lymph node biopsy with no nodal involvement. One patient had a focally positive deep margin.

\section{Treatment and clinical outcomes}

Treatment-related parameters are summarized in Table 2. The median maximum skin dose was $117.5 \%$ amongst our cohort. The median maximum skin dose amongst our $\mathrm{SAVI}^{\circledR}$ patients was $101.15 \%$ and $118 \%$ in our Contura ${ }^{\circledR}$ patients, meeting skin constraints in all our 
Table 1. Summary of baseline patient characteristics

\begin{tabular}{|c|c|}
\hline Patient and tumor characteristics & Value \\
\hline \multicolumn{2}{|l|}{ Age at diagnosis (y) } \\
\hline Median & 62.5 \\
\hline Range & $44-86$ \\
\hline \multicolumn{2}{|l|}{ Treatment device } \\
\hline Contura $^{\oplus}$ & $34(92 \%)$ \\
\hline$\overline{\mathrm{SAVI}} \mathrm{I}^{\oplus}$ & $4(8 \%)$ \\
\hline Neoadjuvant hormonal therapy & $3(8 \%)$ \\
\hline \multicolumn{2}{|l|}{ Adjuvant therapy } \\
\hline Hormonal therapy & $25(68 \%)$ \\
\hline Chemotherapy & $2(5 \%)$ \\
\hline \multicolumn{2}{|l|}{ Histology } \\
\hline Pure DCIS & $13(34 \%)$ \\
\hline IDC & $18(47 \%)$ \\
\hline ILC & $3(8 \%)$ \\
\hline IDC + DCIS & $3(8 \%)$ \\
\hline $\mathrm{ILC}+\mathrm{DCIS}$ & $1(3 \%)$ \\
\hline \multicolumn{2}{|l|}{ Positive receptor status } \\
\hline Estrogen receptor & $33(87 \%)$ \\
\hline Progesterone receptor & $24(63 \%)$ \\
\hline \multicolumn{2}{|l|}{ Histologic grade } \\
\hline 1 & $15(40 \%)$ \\
\hline 2 & $16(42 \%)$ \\
\hline 3 & $5(13 \%)$ \\
\hline Unknown & $2(5 \%)$ \\
\hline \multicolumn{2}{|l|}{ T stage } \\
\hline pTis & $8(21 \%)$ \\
\hline pT1a & $10(26 \%)$ \\
\hline pT1b & $8(21 \%)$ \\
\hline pT1c & $12(32 \%)$ \\
\hline \multicolumn{2}{|l|}{ Nodal status } \\
\hline NO & $24 / 24(100 \%)$ \\
\hline \multicolumn{2}{|l|}{ Margins } \\
\hline Negative & $37(97 \%)$ \\
\hline Focally positive & $1(3 \%)$ \\
\hline
\end{tabular}

DCIS - ductal carcinoma in situ, IDC - invasive ductal carcinoma, ILC - invasive lobular carcinoma
Table 2. Summary of treatment-related parameters

\begin{tabular}{lc} 
Treatment parameter & Value \\
\hline Device to skin distance & \\
\hline Median $(\mathrm{mm})$ & 4.85 \\
\hline $6-7 \mathrm{~mm}$ & $13(34 \%)$ \\
\hline $5-5.9 \mathrm{~mm}$ & $6(16 \%)$ \\
\hline $4-4.9 \mathrm{~mm}$ & $7(18 \%)$ \\
\hline $3-3.9 \mathrm{~mm}$ & $7(18 \%)$ \\
\hline $1-2.9 \mathrm{~mm}$ & $5(14 \%)$ \\
\hline Maximum skin dose & $117.5 \%$ \\
\hline Median & $70.11-128.8 \%$ \\
\hline Range & $113 \%$ \\
\hline Maximum rib dose & $13-150 \%$ \\
\hline Median & $89.5(39.4-114.82)$ \\
\hline Range & \\
\hline PTV_EVAL volume (median-range, cc)
\end{tabular}

Volume PTV_EVAL receiving \% prescribed dose

\begin{tabular}{lc}
\hline $\mathrm{V}_{90}$ (median-range) & $99 \%(92-100 \%)$ \\
\hline $\mathrm{V}_{95}$ (median-range) & $96.3 \%(88.5-99.7 \%)$ \\
\hline $\mathrm{V}_{100}$ (median-range) & $91.8 \%(86.78-98.5 \%)$
\end{tabular}

Volume normal tissue receiving \% prescribed dose

\begin{tabular}{lc}
\hline$V_{150}$ (median-range) & 27 cc (15.8-50) \\
\hline$V_{200}$ (median-range) & $9.3 c c(5-18)$ \\
\hline Dose non-uniformity ratio (mean-range) & $0.33(0.19-0.56)$ \\
\hline Dose homogeneity index (mean-range) & $0.67(0.44-0.81)$
\end{tabular}

$V_{90}, V_{95}, V_{100}, V_{150}, V_{200}$ - the percentage of the prostate volume receiving $90 \%$, $95 \%, 100 \%, 150 \%, 200 \%$ of the prescribed dose or more

patients. The majority of our other constraints were also met during the treatment planning process. The average dose non-uniformity ratio and dose homogeneity index in our cohort were 0.33 and 0.67 , respectively. Representative axial sections of the plans are shown in Figure 1.

After a median follow-up of 47.5 months, one patient experienced an ipsilateral breast recurrence and is currently undergoing work-up for a planned mastectomy. Of note, she had been unable to tolerate adjuvant hormonal therapy after completion of her APBI. A second patient experienced axillary recurrence, which was treated with hormonal therapy, due to her not being a surgical candidate. None of the recurrences were within the treated PTV volume.

\section{Toxicities and cosmesis}

Per the RTOG acute radiation morbidity criteria, seven $(18 \%)$ lesions had no skin or subcutaneous tissue re- 

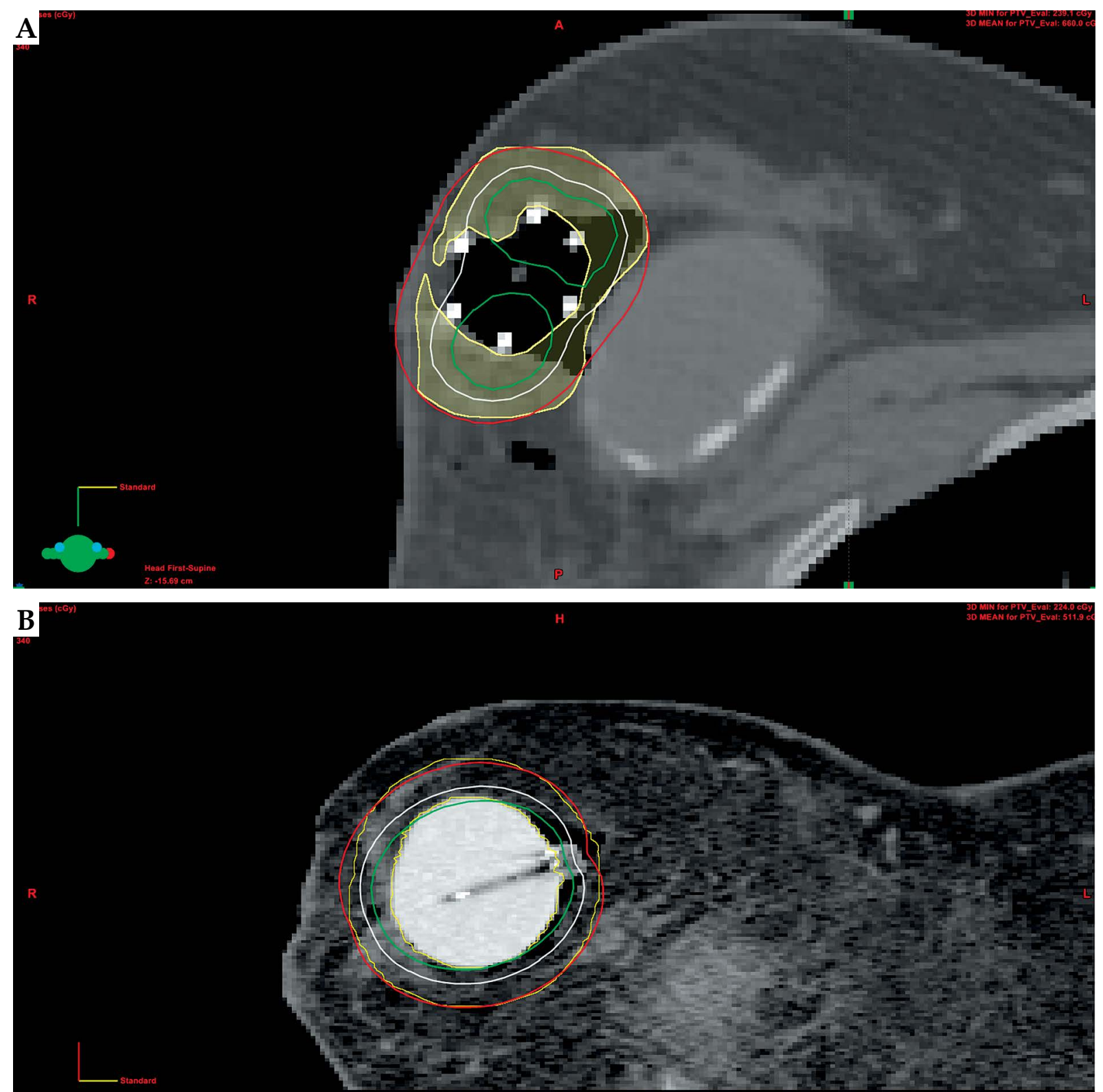

Fig. 1. Representative axial sections showing the isodose distributions around the device in relation to the skin. Fig. 1A shows a SAVI ${ }^{\circledR}$ device and Fig. 1B a Contura ${ }^{\circledR}$ device. Patient in Fig. 1A also had a pre-existing breast implant. Green lines represent $200 \%$, white $150 \%$, and red $100 \%$ prescribed isodose line. The outer yellow lines represent the PTV_EVAL volume

actions, $22(58 \%)$ lesions were reported to have grade 1 reactions, and $9(24 \%)$ treated lesions experienced grade 2 reactions. Fifteen $(40 \%)$ patients experienced no late skin or subcutaneous tissue side effects per the RTOG criteria, 21 (55\%) experienced grade 1 toxicities, and two (5\%) patients did not have their late toxicities recorded. One patient with $6 \mathrm{~mm}$ skin spacing had to undergo mastectomy nearly 54 months after completion of treatment due to mastitis. Cosmetic outcomes as measured per the Harvard cosmesis scale were graded as excellent in $24(63 \%)$, good in $11(29 \%)$, and not reported in $3(8 \%)$ cases. Summary of clinical outcomes is presented in Table 3.

We attempted to determine if there was any correlation between the device to skin distance and the late toxicities and cosmesis. There was no correlation between skin spacing and acute toxicities $(p=0.213)$ or late toxicities $(p=0.28)$ but trended towards significance when examining the cosmetic outcome $(p=0.0926)$. However, all patients with skin spacing of $3 \mathrm{~mm}$ or less experienced acute (Figure 2A), late toxicities (Figure 2B), and worse cosmesis (Figure 2C). Representative images of patients immediately after treatment and outcomes at later time points are displayed in Figure 3.

\section{Discussion}

Although brachytherapy APBI is only appropriate for a selected population of women with early stage breast cancer $[5,6,7,8]$, it represents a valuable alternative in terms of reducing the treatment time, cost, and volume 
Table 3. Summary of toxicities and long-term cosmetic outcome reported in 38 treated lesions

\begin{tabular}{lc} 
Clinical outcomes & Value \\
\hline Acute toxicity & $7(18 \%)$ \\
\hline None & $22(58 \%)$ \\
\hline Grade 1 & $9(24 \%)$ \\
\hline Grade 2 & $15(40 \%)$ \\
\hline Nate toxicity & $21(55 \%)$ \\
\hline Grade 1 & $2(5 \%)$ \\
\hline Unknown & $24(63 \%)$ \\
\hline Cosmetic outcomes & $11(29 \%)$ \\
\hline Excellent & $3(8 \%)$ \\
\hline Good & $1(3 \%)$ \\
\hline Unknown & $0(0 \%)$ \\
\hline Recurrences & \\
\hline None & $1(94 \%)$ \\
\hline Ipsilateral breast & \\
\hline Ipsilateral nodal & \\
\hline Distant & \\
\hline
\end{tabular}

of irradiated normal tissue. However, since in one of the earliest APBI registries' report skin spacing of $<7 \mathrm{~mm}$ was one of the factors associated with a worse cosmetic outcome [4], radiation oncologists have been hesitant to treat patients with close skin spacing using APBI. Several advances have been made since including the arrival of multi-lumen applicators in the form of Contura ${ }^{\circledR}$ and multi-catheter applicators in the form of SAVI ${ }^{\circledR}$. These newer devices allow some flexibility in dose distribution, therefore, theoretically allowing patients with close skin spacing to undergo treatment with acceptable outcomes as long as the skin dose constraints are met [15].

Two studies since have evaluated patients with close skin spacing who have undergone treatment with SAVI ${ }^{\circledR}$ or Contura ${ }^{\circledR}$. In the initial SAVI ${ }^{\circledR}$ experience, Yashar and colleagues after a median follow-up of 21.1 months reported excellent cosmetic outcome. Their population included some patients with skin spacing of less than $7 \mathrm{~mm}$ with a median maximum skin dose of $80 \%$ of the prescribed dose [11]. However, they did not report the number of patients with close skin spacing, nor did they report clinical outcomes specifically for those with close skin spacing. In a separate report, Lee et al. examined short-term outcomes in 26 patients treated with multilumen balloon brachytherapy. After a median follow-up of 9 months, they reported excellent or good cosmetic outcomes in $92.3 \%$ of their patients. Their median maximum skin dose was $118.2 \%$ but the majority of their patients $(62 \%)$ had skin spacing between 5 to $7 \mathrm{~mm}$ [12].
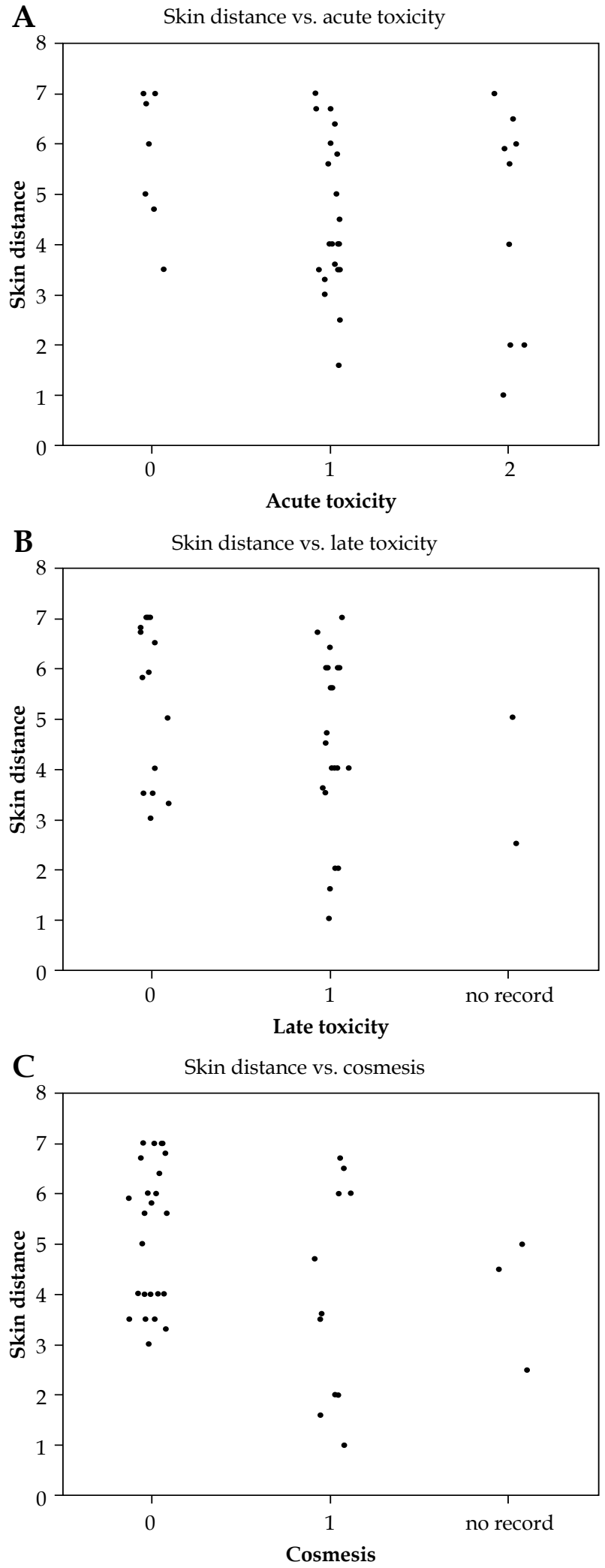

Fig. 2. A) The device to skin distance ( $\mathrm{mm}$ ) graphed against acute skin or subcutaneous tissue toxicity per RTOG criteria. B) The device to skin distance $(\mathrm{mm})$ graphed against late skin or subcutaneous tissue toxicity per RTOG criteria. C) The device to skin distance $(\mathrm{mm})$ graphed against the Harvard cosmesis scale (1 excellent, 2 good) 

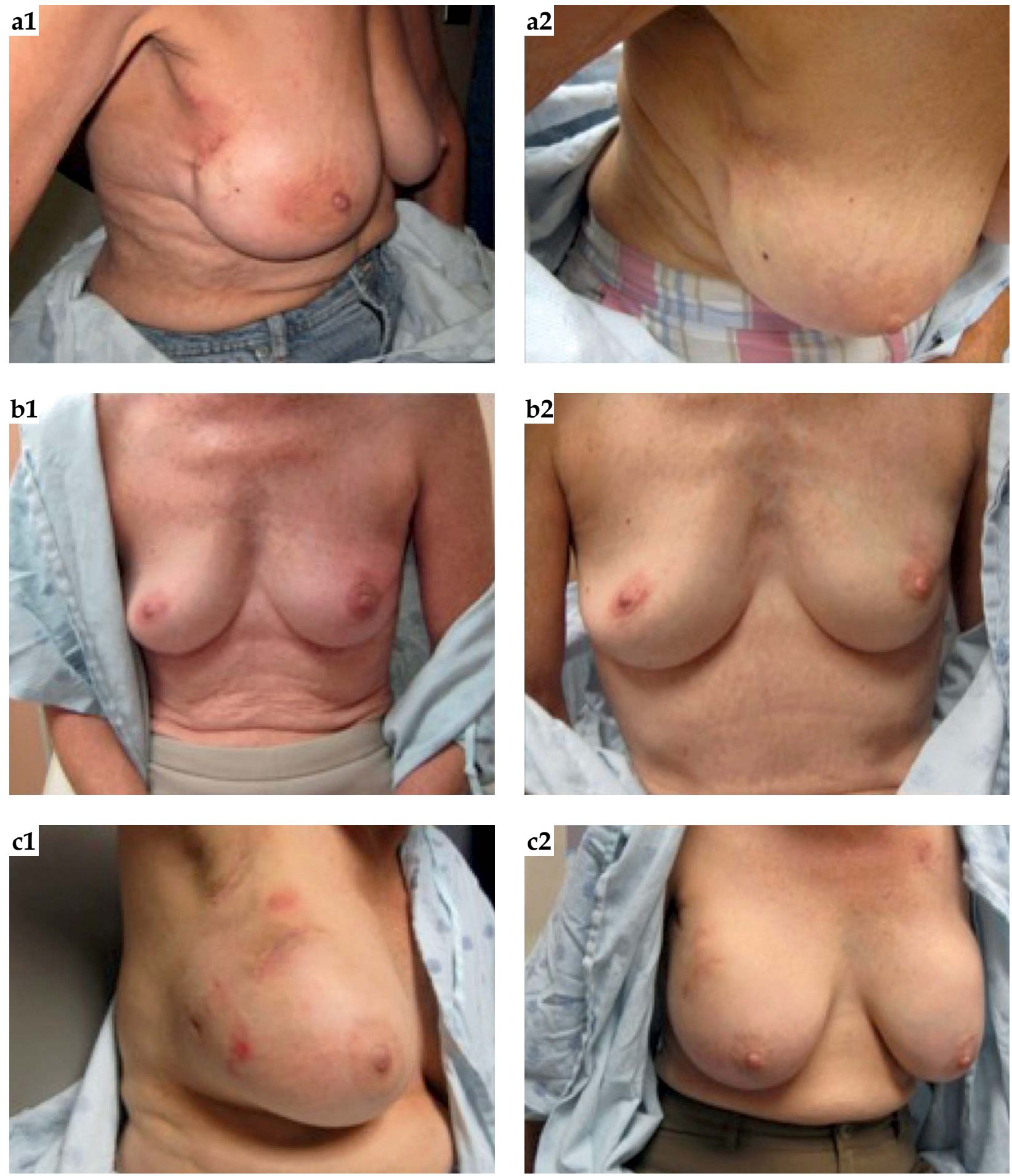

\begin{tabular}{|l|c|c|c|c|}
\hline Row & Skin spacing $(\mathrm{mm})$ & Follow-up time (1) & Follow-up time (2) & Cosmesis (Harvard scale) \\
\hline a & 3.0 & 2 weeks & 23 months & Excellent \\
\hline b & 6.0 & 2 weeks & 24 months & Excellent \\
\hline c & 3.3 & 2 weeks & 11 months & Excellent \\
\hline
\end{tabular}

Fig. 3. Follow-up images from representative patients. Follow-up times and relevant clinical parameters are reported below for each row. The last pictured follow-up date does not necessarily represent the last follow-up date in clinic 
We have now reported the longest follow-up and the largest cohort of patients with close skin spacing treated with multi-lumen or multi-catheter applicators. Most of our patients had excellent or good cosmesis (92\%) after a median follow-up of 47.5 months. Three of our patients had been treated with neoadjuvant hormonal therapy prior to treatment but this did not result in a change in the size of their tumor or their eventual treatment. The rates of both acute and late toxicities were acceptable with only $24 \%$ of patients experiencing acute grade 2 toxicities and no late grade 2 toxicities. We were also able to keep our maximum skin dose within our pre-specified goal (median, $117.5 \%$ ) without compromising other dosimetric constraints. The median maximum skin dose in the SAVI ${ }^{\circledR}$ cohort was lower at $101.15 \%$; although, it is difficult to draw any definitive conclusions since only $8 \%$ of our patients were treated with $\mathrm{SAVI}^{\circledR}$.

There was no statistically significant correlation between the device to skin distance and the occurrence of acute or late toxicities but there was a trend towards significance in terms of the cosmetic outcome. However, if we examined the patients with $3 \mathrm{~mm}$ or less skin spacing, all experienced some acute and late toxicity, and all except one had good cosmetic outcome as opposed to excellent.

With the updated guidelines regarding which patients can safely and appropriately be treated with APBI [16], it is important to consider each patient's specific disease and treatment related characteristics before deciding on the specific APBI delivery mode. In the interim analysis of the RAPID trial, APBI using external beam radiation therapy was shown to have worse cosmetic outcome compared to whole breast irradiation [17], and should ideally be avoided in patients who highly value their cosmetic outcome. Accelerated partial breast irradiation using interstitial needle placement is still an acceptable option with long-term data supporting great clinical and cosmetic outcomes but is limited to only centers with ongoing experience given the technical expertise needed for needle placement. To our knowledge, there is no current data of examining cosmetic outcomes using this technique in relation to the skin to needle spacing. Intraoperative radiation therapy is also considered appropriate treatment for a few patients with early stage breast cancer who meet certain criteria. Although patients in the TARGIT trial were shown to have better cosmetic outcome compared to their whole breast cohort [18]; no cosmetic results have been reported to-date for the ELIOT trial [19]. Additionally, there are no data regarding the safety and cosmesis of IORT in patients with lesions in proximity to their skin. Therefore, it is important to consider a tumor's proximity to skin when planning on a potential APBI treatment post-lumpectomy, so that the correct modality for delivering APBI can be selected.

\section{Conclusions}

Based on our results, it appears that patients with close skin spacing of $7 \mathrm{~mm}$ or less can potentially be treated safely with multi-lumen or multi-catheter applicators with good preliminary clinical and cosmetic outcome. Nevertheless, given the limited number of patients in our study and the retrospective nature of our investigation, caution should be utilized in selecting the optimal patients and minimizing risk of toxicity by limiting dose to the skin. A maximum skin dose constraint of $125 \%$ of prescribed dose for Contura ${ }^{\circledR}$ devices and $110 \%$ for SAVI ${ }^{\circledR}$ devices is a reasonable target based on our data and Lee and colleague's report [12]. The patients with $3 \mathrm{~mm}$ or less skin spacing are at higher risk of acute and late toxicities, and should be advised accordingly before their planned treatment but they can still safely be treated with good outcomes. Therefore, close skin spacing should no longer be considered an automatic exclusion criterion for patients who are set to undergo APBI with multi-channel applicators.

\section{Disclosure}

Authors report no conflict of interest.

\section{References}

1. Vicini FA, Recht A, Abner A et al. Recurrence in the breast following conservative surgery and radiation therapy for early-stage breast cancer. J Natl Cancer Inst Monogr 1992; 11: 33-39.

2. Bitter SM, Heffron-Cartwright $P$, Wennerstrom $C$ et al. WBRT vs. APBI: an interim report of patient satisfaction and outcomes. J Contemp Brachytherapy 2016; 8: 17-22.

3. Smith GL, Huo J, Giordano SH et al. Utilization and Outcomes of Breast Brachytherapy in Younger Women. Int J Radiat Oncol Biol Phys 2015; 93: 91-101.

4. Goyal S, Khan AJ, Vicini F et al. Factors associated with optimal cosmetic results at 36 months in patients treated with accelerated partial breast irradiation (APBI) on the American Society of Breast Surgeons (ASBrS) MammoSite ${ }^{\circledR}$ Breast Brachytherapy Registry Trial. Ann Surg Oncol 2009; 16: 24502458.

5. Shah C, Vicini F, Wazer DE et al. The American Brachytherapy Society consensus statement for accelerated partial breast irradiation. Brachytherapy 2013; 12: 267-277.

6. The American Society of Breast Surgeons. Consensus Statement for Accelerated Partial Breast Irradiation [online]. (2016, 06 30), retrieved from https://www.breastsurgeons. org/statements/PDF_Statements/APBI.pdf (2011).

7. Smith BD, Arthur DW, Buchholz TA et al. Accelerated partial breast irradiation consensus statement from the American Society for Radiation Oncology (ASTRO). Int J Radiat Oncol Biol Phys 2009; 74: 987-1001.

8. Polgár C, Van Limbergen E, Pötter R et al. Patient selection for accelerated partial-breast irradiation (APBI) after breastconserving surgery: recommendations of the Groupe Europeen de Curietherapie-European Society for Therapeutic Radiology and Oncology (GEC-ESTRO) breast cancer working group based on clinical evidence (2009). Radiother Oncol 2010; 94: 264-273.

9. Shah C, Wobb J, Manyam B et al. Accelerated partial breast irradiation utilizing brachytherapy: patient selection and workflow. J Contemp Brachytherapy 2016; 8: 90-94.

10. Niehoff $P$, Polgár C, Ostertag H et al. Clinical experience with the MammoSite ${ }^{\circledR}$ radiation therapy system for brachytherapy of breast cancer: results from an international phase II trial. Radiother Oncol 2006; 79: 316-320.

11. Yashar CM, Scanderbeg D, Kuske R et al. Initial clinical experience with the Strut-Adjusted Volume Implant $\left(\mathrm{SAVI}^{\circledR}\right)$ breast brachytherapy device for accelerated partial-breast irradiation (APBI): first 100 patients with more than 1 year of follow-up. Int J Radiat Oncol Biol Phys 2011; 80: 765-770. 
12. Lee K, Quillo A, Dillon D et al. Acute toxicity and early cosmetic outcome in patients treated with multilumen balloon brachytherapy with skin spacing $\leq 7.0$ millimeters. J Contemp Brachytherapy 2012; 4: 8-13.

13. Cox JD, Stetz J, Pajak TF. Toxicity criteria of the radiation therapy oncology group (RTOG) and the European organization for research and treatment of cancer (EORTC). Int J Radiat Oncol Biol Phys 1995; 31: 1341-1346.

14. Harris JR, Levene MB, Svensson G et al. Analysis of cosmetic results following primary radiation therapy for stages I and II carcinoma of the breast. Int J Radiat Oncol Biol Phys 1979; 5: 257-261.

15. Gurram L, Wadasadawala T, Joshi K et al. Multi-catheter interstitial brachytherapy for partial breast irradiation: an audit of implant quality based on dosimetric evaluation comparing intra-operative versus post-operative placement. J Contemp Brachytherapy 2016; 8: 116-121.

16. Correa C, Harris EE, Leonardi MC et al. Accelerated Partial Breast Irradiation: Executive summary for the update of an ASTRO Evidence-Based Consensus Statement. Pract Radiat Oncol 2016 (in press).

17. Whelan TJ, Olivotto I, Parpia S et al. Interim toxicity results from RAPID: a randomized trial of accelerated partial breast irradiation (APBI) using 3D conformal external beam radiation therapy (3D CRT). Int J Radiat Oncol Biol Phys 2013; 85: 21-22.

18. Keshtgar MRS, Williams NR, Bulsara M et al. Objective assessment of cosmetic outcome after targeted intraoperative radiotherapy in breast cancer: results from a randomized controlled trial. Breast Cancer Res Treat 2013; 140: 519-525.

19. Veronsesi U, Orecchia R, Maisonneuve P et al. Intraoperative radiotherapy versus external radiotherapy for early breast cancer (ELIOT): a randomized controlled equivalence trial. Lancet Oncol 2013; 14: 1269-1277. 